\title{
Web-based audience response system for quality feedback in first year engi- neering
}

\section{Dr. Brian M Frank, Queen's University}

Brian Frank is an associate professor in Electrical and Computer Engineering, where he has taught courses in electronics and wireless systems. He is the DuPont Canada Chair in Engineering Education Research and Development, and the Director of Program Development in the Faculty of Engineering and Applied Science where he works on engineering curriculum development, program assessment, and developing educational technology. He is a co-founder of the Canadian Engineering Education Association and is currently coordinating the Engineering Graduate Attribute Development Project, working with National Council of Deans of Engineering and Applied Science and the Canadian Engineering Accreditation Board, to develop national guidelines and resources for outcomes assessment in engineering education. 


\title{
Web-based audience response system for quality feedback in first year engineering
}

\begin{abstract}
The paper will describe the pilot of a commercial web-based audience response system to enhance feedback between course instructor and students in a first year engineering course. Students were simultaneously using a clicker based system in other courses, so perceptions about the two systems are reported. In addition to functions provided by most response systems, the web-based system allows open-text response to questions, allows student to initiate questions to the instructor, and allows students to flag when they are confused using either a smartphone or laptop. Students generally felt that the system is more engaging, and that being able to respond to questions in open-text form, and see other students' responses, is useful. Sporadic problems with WiFi access prevented some students from accessing the system, and many students felt that the advantages of the system were offset by the network access problems and the need to carry a laptop to class. The instructor's perspective is that these kinds of systems offer possibilities for enhancing the quality and quantity of feedback between students and the instructor, but will require adaptation in teaching style and student perceptions about lectures, and reliable technical systems.
\end{abstract}

\section{Introduction}

In higher education feedback between instructor and student is most commonly limited to that from the instructor to the student in the form of grades for correct and incorrect solutions to problems, and occurs relatively infrequently over the duration of a course. Advancements in computer technology are beginning to enable faster and more regular feedback by computerized scoring of student work (Jordan \& Mitchell, 2009) and computer-supported peer review (Wood, 2009), and considerable success has been found by enhancing lecture time using an interactive classroom format and frequent in-class assessment (Hake, 1998; Knight \& Wood, 2005).

Instructors employing in-class assessment frequently turn to technology including audience response systems (ARS) which are most often dedicated handheld transmitters often known as "clickers", which include TurningPoint ("Turning Technologies," n.d.) and iClicker ("iClicker," n.d.). These approaches have been widely used and their impact on engagement and learning has been presented widely.

Clickers have been shown to improve student outcomes (Caldwell, 2007) such as improved exam scores (Knight \& Wood, 2005) student engagement (Van Dijk, Van Der Berg, \& Van Keulen, 2001), comprehension, and learning, attendance (Caldwell, 2007), and students generally like clickers (Bunce, VandenPlas, \& Havanki, 2006). When combined with small group work in 
approaches like peer instruction, regular-in class feedback has been shown to yield significant learning gains as measured by concept inventories (Hake, 1998).

Clickers allow bidirectional feedback between the students and instructor (Wood, 2004), and students report benefit from comparing their answers with the rest of the class (Bunce et al., 2006). In a comprehensive synthesis of over 800 meta-analyses, Hattie showed that one of the most significant effects on learning is feedback from student to the instructor (Hattie, 2008, 2009). According to Hattie,

...the most powerful feedback occurs when feedback is to the instructor: about how well they have taught, who they taught well, what they have or have not taught well. The trickle-down effect from such assessment that informs the instructor down to the student is much greater than the teaching and learning that comes from assessment directly to the student.(Hattie, 2009, p. 11).

When teachers seek, or at least are open to, feedback from students as to what students know, what they understand, where they make errors, when they have misconceptions, when they are not engaged, then teaching and learning can be synchronised and powerful.(Hattie, 2009, p. 13)

Unfortunately, feedback can have detrimental effects on learning; a large meta-analysis found that a third of effects studied had a negative impact on learning (Kluger \& DeNisi, 1996). Feedback has high impact when provided on familiar tasks where goals are specific and challenging, there is low threat to self-esteem, the task complexity is low, and attention is directed to the task or meta-cognitive processing (e.g. "You already know the key features of the opening of an argument. Check to see whether you have incorporated them in your first paragraph.") rather than the personal level ("You are a great student") (Kluger \& DeNisi, 1996).

Unfortunately clicker-based systems present limitations to the instructor, including inability or difficulty in allowing students to provide text responses, and to initiate discussion. Clickers allow students to respond to instructive questioning in only a limited form of Socratic dialog, as they do not allow open-text responses, nor student-initiated questions. When course objectives include literacy, critical thinking, and complex problem, solving "clickers" enforce limits on the richness of feedback possible during class.

Technology has begun to make it possible to provide richer feedback, as vendors are making web-based response systems possible, e.g. tools by established ARS companies like ResponseAnywhere by Turning Technologies and web>clicker by $\mathrm{i}>$ Clicker, and newer vendors like TopHat Monocle and CourseModo. These provide the opportunity to use technology to emulate the kind of interaction possible in a smaller group session.

Web-based ARS can enable high impact feedback between instructors and students that presents a low threat to student self-esteem (due to the possibility of making responses anonymous and not connected to course grades), and directs attention to task performance, and to meta-cognitive 
process. Use in class allows a very short feedback cycle that allows instructors to address misperceptions and enrich understanding of complex issues.

\section{Course context}

The study was set in the first year of an undergraduate engineering program at Queen's University, a medium-sized university in Canada where TurningPoint clickers have been used for many years. In the fall of the 2012-2013 academic year first-year students used two different ARS systems in different courses: the introductory statics and calculus courses continued to use the ResponseCard RF from Turning Technologies ("Turning Technologies," n.d.) that allows multiple choice and true/false responses, and the engineering design and professional practice course, [course name hidden], used as the context for this study piloted a web-based response system, TopHat Monocle ("Top Hat Monocle," n.d.). The system allows students to use their laptops, tablets, smartphones, and SMS to interact with the instructor, and relies on WiFi and/or cellular networks for communication to the vendor's web server. Students used the ARS systems in lectures in the three courses; the class of approximately 650 students is divided into three roughly equal sized lecture sections.

It was decided to allow use of the system in APSC-100 to be optional for several reasons. In previous years students complained about the in-class WiFi network, and though the system was improved and tested prior to this study, the reliability of the WiFi was still uncertain.

Additionally, laptops and smartphones are not required in the program, so not all students would have them. It would have been possible to make the system mandatory by providing paper-based questions for the small number of students with connection problems, or without laptop or smartphone, but for the sake of simplicity that option wasn't selected. Most students did use the system. The use of the clickers in the statics and calculus course was mandatory in the form of participation grades. Students were required to purchase the clickers for those courses, and the web-based ARS system was made free by licensing it through the course budget.

APSC-100 is a team-based, project-based course to promote a sense of curiosity about engineering, and promote creative thought. The course is divided into three modules: Module 1. Problem analysis and modeling; Module 2. Experimentation and measurement; Module 3: Engineering design. Each of these is one semester long and equivalent in weight to a standard one-semester engineering course. This study was embedded into the delivery of the problem analysis and modeling module (module 1).

The problem analysis and modeling module (module 1) is a semester-long integrative experience that uses concepts from engineering sciences, natural sciences, and mathematics courses to solve complex open-ended problems. The course is structured around three complex problems known as model-eliciting activities (MEAs) that were addressed sequentially in three-week blocks over the semester. MEAs are problems used in class and subsequently finished by small teams and submitted for grades, that are set in a realistic context that requires the learner to document not only the solution to the problem, but also their process for solving it (Frank \& Kaupp, 2012; Shuman, Besterfield-Sacre, Bursic, Vidic, \& Sieworiek, 2012). The situations described in the MEAs require students to create and use a mathematical model of a physical system using 
MATLAB, and deal with professional issues including ethical dilemmas, conflicting information, and incorrect/missing information (Frank, Strong, Sellens, \& Clapham, 2012).

The module learning outcomes are such that open-text responses are desirable; the learning outcomes are:

1. Apply a prescribed process for solving complex contextualized client-driven problems (ill-defined, multiple constraints, problems, unknown information)

2. Create and apply appropriate quantitative model and analysis to solve problems.

3. Effectively communicate technical information following a prescribed format and using standard grammar and mechanics.

4. Apply concepts including occupational health and safety principles, economics, law, and equity to engineering problems.

5. Identify and resolve a simple ethical dilemma by applying professional codes of ethics and engineering standards.

6. Apply critical and creative thinking principles to solve contextualized problems.

7. Apply numerical modeling tool (MATLAB) to create model used for solving complex problems.

In most weeks the one-hour lecture followed a structure like:

- The instructor presented a recent problem or news article related to the lecture objective; in some cases the students respond to a problem posed using the web-based ARS in teams

- The instructor presented or reviewed the problem being solved during the three-week session

- The instructor led a short discussion on a topic related to the problem being studied

- Students work on some component of the problem in small groups which will contribute to the solution; in many cases this included an open-text question answered using the web-based ARS.

The course was structured help students develop confidence and skills in solving complex engineering problems - problems for which all information is not known, in which there is ambiguity, where the goals are not necessarily clearly defined.

\section{Implementation of the web-based ARS}

After some review of web-based ARS systems, TopHat Monocle was selected. It has the following features according to the vendor ("Top Hat Monocle," n.d.):

- Conduct polls or quizzes where the answer is multiple choice, numeric, or word answer, and see the results come in live on your computer or smart-phone

- Run interactive demonstrations that students can do on their laptops or smart phones in class (or at home)

- Help stimulate discussion in class by polling your students with open ended questions, and reward students for participation or for helping each other out with questions. 
- Allow your students to complete selected questions or demos at home outside the classroom, and allow them to review the questions for study purposes after they have been taken up during the lecture.

- Answers submitted to questions and demos are graded automatically and tracked in the gradebook.

Figure 1 shows an example of a typical instructor view in the web-based ARS. Along the top under the green "Feedback" heading is a viewer that shows the number of student who flag that they are confused by the current discussion. A list of instructor-generated questions is shown under the red "Questions" module on the left side, and the currently open discussion is shown under the purple heading. The instructor has the option to control what questions are currently open, and what information the students can see.

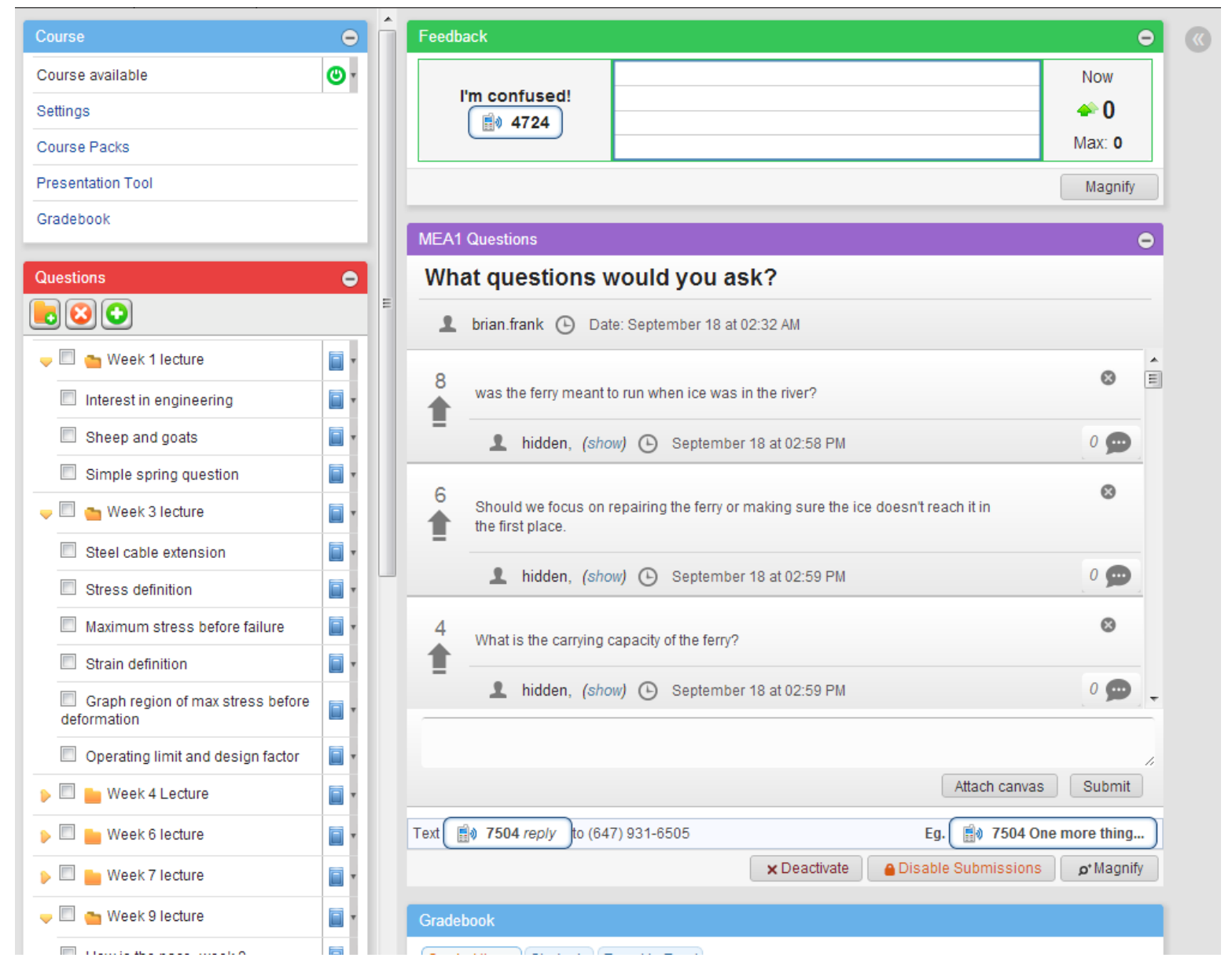

Figure 1 - Typical instructor view of the web-based ARS. 
The instructor can create discussion forums to be used for open-text responses to specific questions, or to allow students to ask a question of the instructor at any time. Figure 2 shows an example of a discussion forum that was open to students throughout the course, enabling them to ask a question of the course instructor at any time.

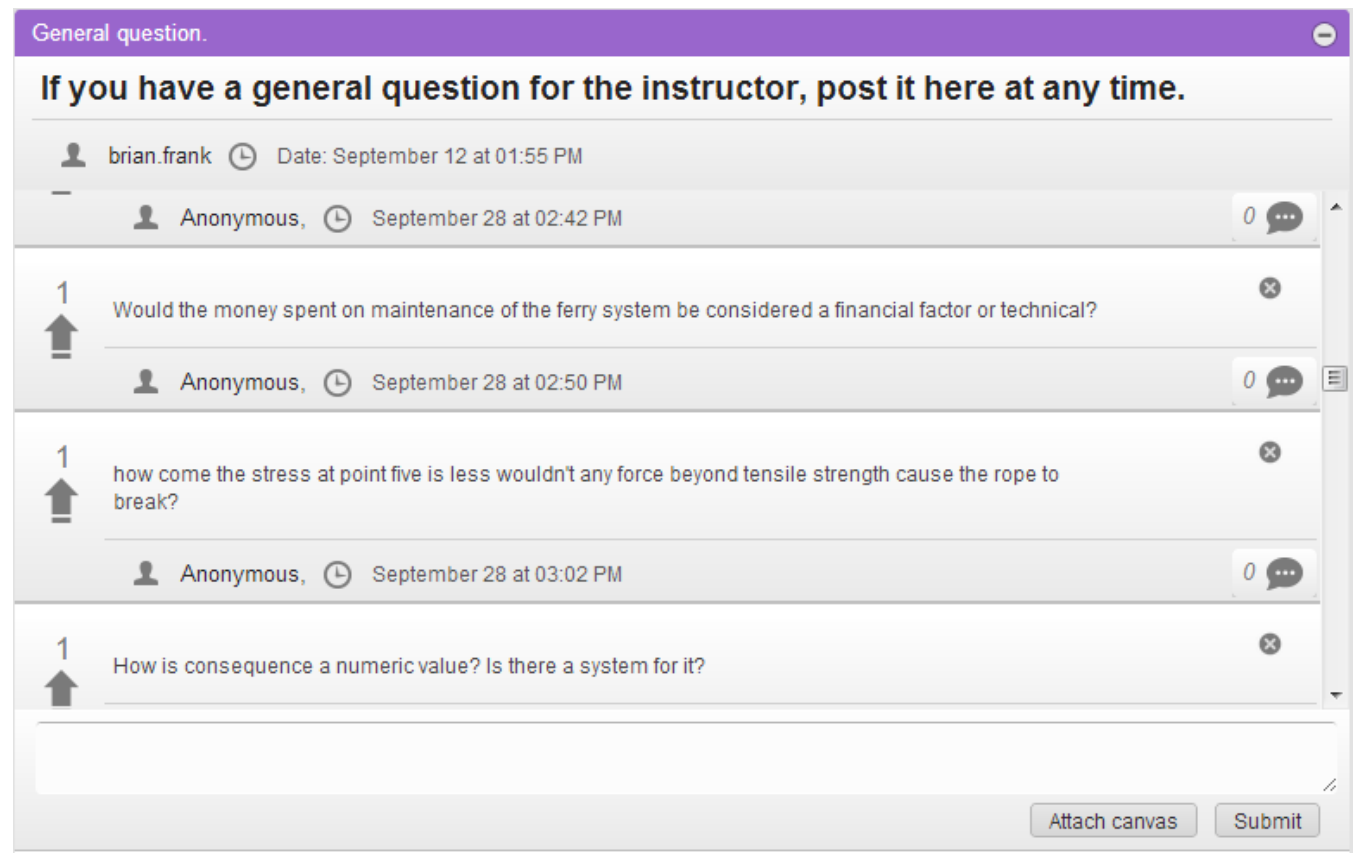

Figure 2 - Discussion forum to allow students to ask questions at any time.

The example in Figure 3 shows the instructor's view of a multiple-choice problem used in [course name masked]. The instructor can post images in the questions, and view a histogram of student responses; generally the functionality for these kinds of questions is similar to handheld clickers.

The power of the tool is as a complement to closed-ended problems. Since the course objectives centred around critical thinking and open-ended problem solving, a web-based ARS allows the instructor to broaden the types of questions asked. For example, one of the MEAs involved a scenario in which students took the role of engineers on a building project, and were presented a small cash gift as a token of appreciation from a contractor. Prior to discussing ethical principles and codes of ethics, the students were asked why the contractor might present such a gift, and whether that was an issue. Figure 4 below shows the instructor's view of students responses, submitted in a text box in their web browsers, to the open-text question. 
Details Reports

\# Submissions 193

\section{Question:}

In the diagram below, the maximum stress applied to the material before it fails is at point

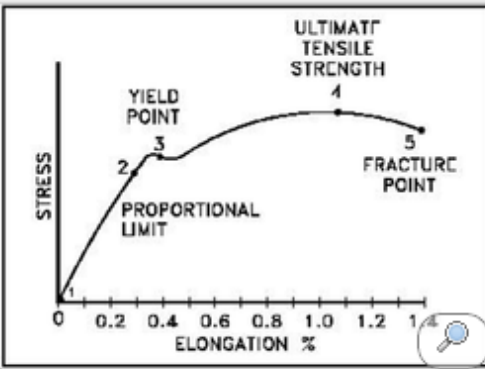

b $\quad 2$

c 3

d 4

e 5

Figure 3 - Multiple choice question with embedded image.

Gitt given to engineer

Why might the gift have been given, and how would you respond?

$\Omega$ brian.frank () Date: November 06 at 01:55 AM

3 IItjkI, ৬

$\checkmark+$

1

Contractor may want to make some short cuts to save them money or may want

$\boldsymbol{\otimes}$ you to choose a more expensive way method so they make more money. Gift to get you on their side.

2

() November 07 at 03:39 PM

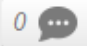

1 The gift might have been given if you accommodated the contractor in a certain

$\boldsymbol{x}$ way to help them out. Maybe you could give the gift as charity.

1

()) November 07 at $03: 39$ PM

1 Because you did a good job

×

Figure 4 - Open-text question about an ethical dilemma. 
Some sample responses were then shown to the class, and used to start a discussion on ethical principles. In this way students could see how other students thought, initiate a discussion, and allow the instructor to consider unexpected student perspectives. The responses were used to prompt some thought on how an engineer might reason. The instructor then led a discussion about ethical principles and codes of ethics, and then asked a follow-up multiple-choice question, shown in Figure 5.

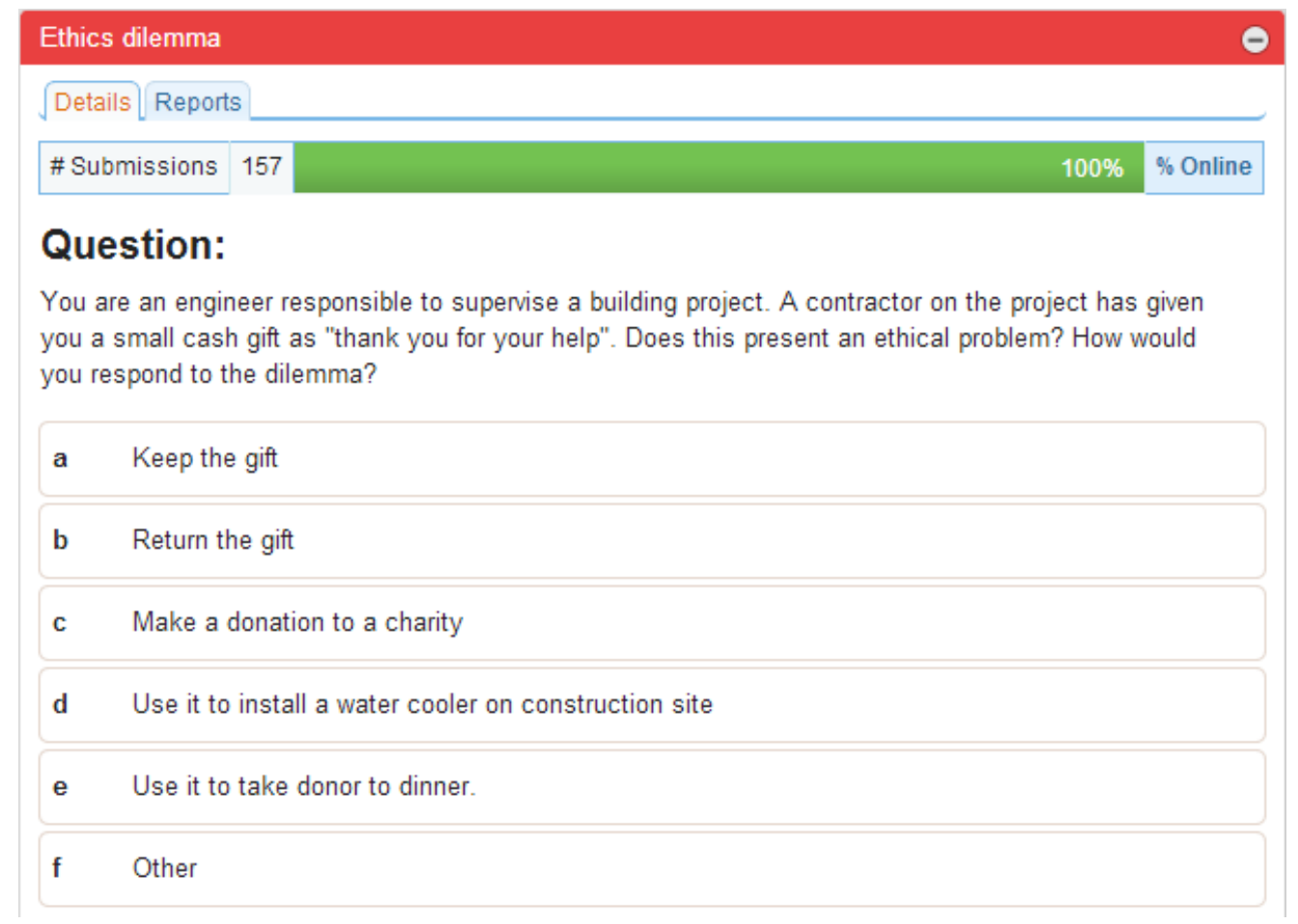

\section{Figure 5 - Multiple choice question about an ethical dilemma.}

The system was also used in helping students identify questions that could be asked to help solve a complex, under-defined problem. For example, students were given a problem in which a cable ferry failed, and they were accident investigators. They were asked to think of the kinds of questions they might ask, prior to a class discussion about questioning. An example of some responses is shown in Figure 6. 


\section{What questions would you ask?}

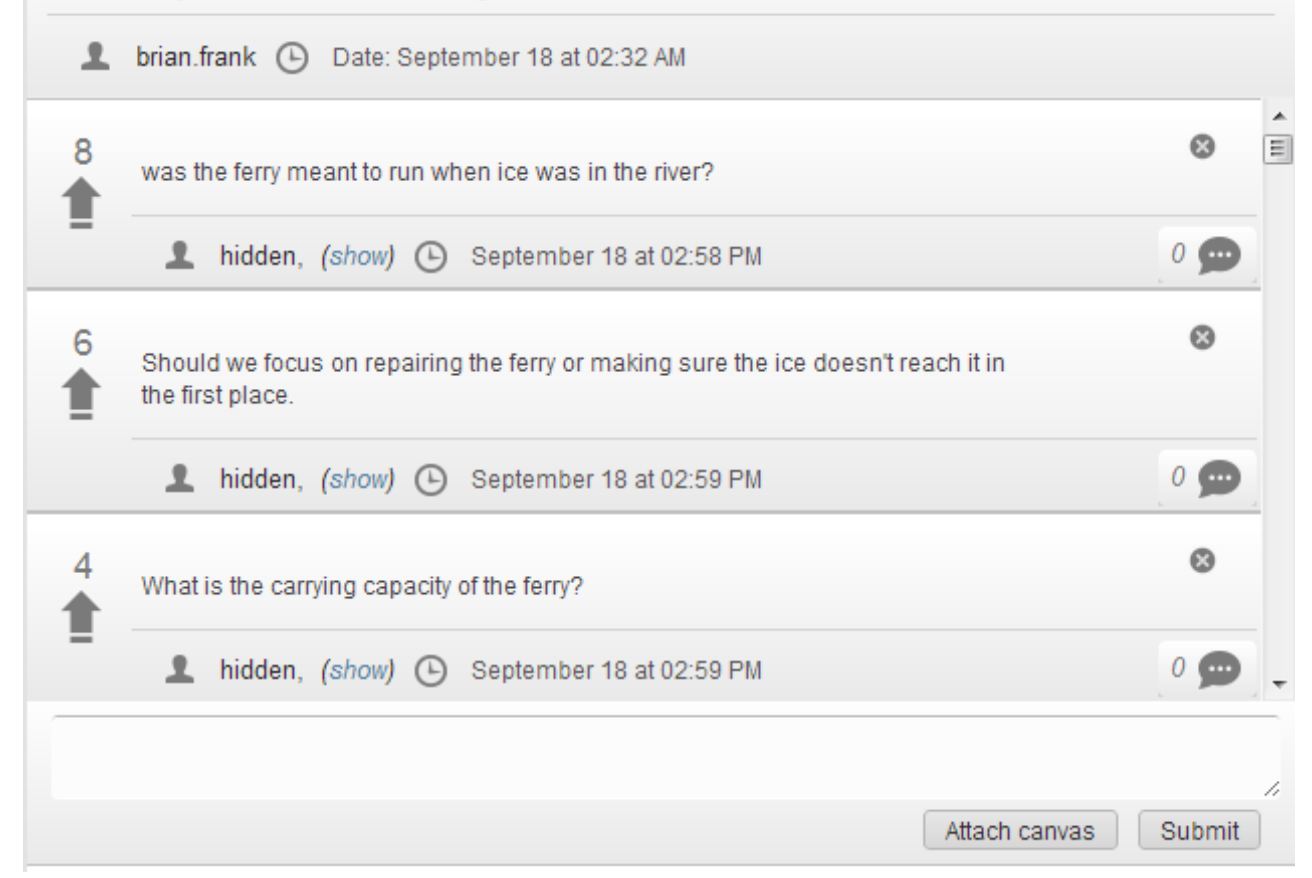

Figure 6 - Open text question to elicit types of questions to be posed when solving a complex problem.

Although the use of the web-based ARS was voluntary, response rates for most questions was approximately $60-75 \%$ of the course enrollment, and since class attendance was lower than the course enrollment, the majority of the students used the system. Dips in the participation rate occurred when attendance dropped, often due to midterm exams or other activities.

\section{Final survey}

At the end of the semester students were asked a series of closed ended and open-ended questions about the web-based ARS. The questions asked were as follows:

1. I find that having to use my smartphone/laptop in class for a response system is distracting (I'm tempted to Facebook, do email, etc. rather than participating in class lecture and activities).

2. The ability for students to ask questions at any time using the discussion forum is useful.

3. It is helpful when the instructor picks sample student responses to discuss in class.

4. TopHat's ability to ask open-ended text questions so that the instructor can show samples of student ideas, helps me to learn.

5. On average I experienced technological problems using TopHat in weeks 3-12:

6. I found that I didn't use a smartphone because I found it less reliable than using a laptop with the TopHat system. 
7. I think that a web-based response system like TopHat can be useful for keeping students engaged during lecture time.

8. If the WiFi network connection issues were resolved and you were able to reliably respond to questions on a smartphone, would you prefer to use a system like TopHat, or prefer clickers?

The response rate to the survey was approximately $50 \%$, due to a lower-than-usual attendance at the final lecture.

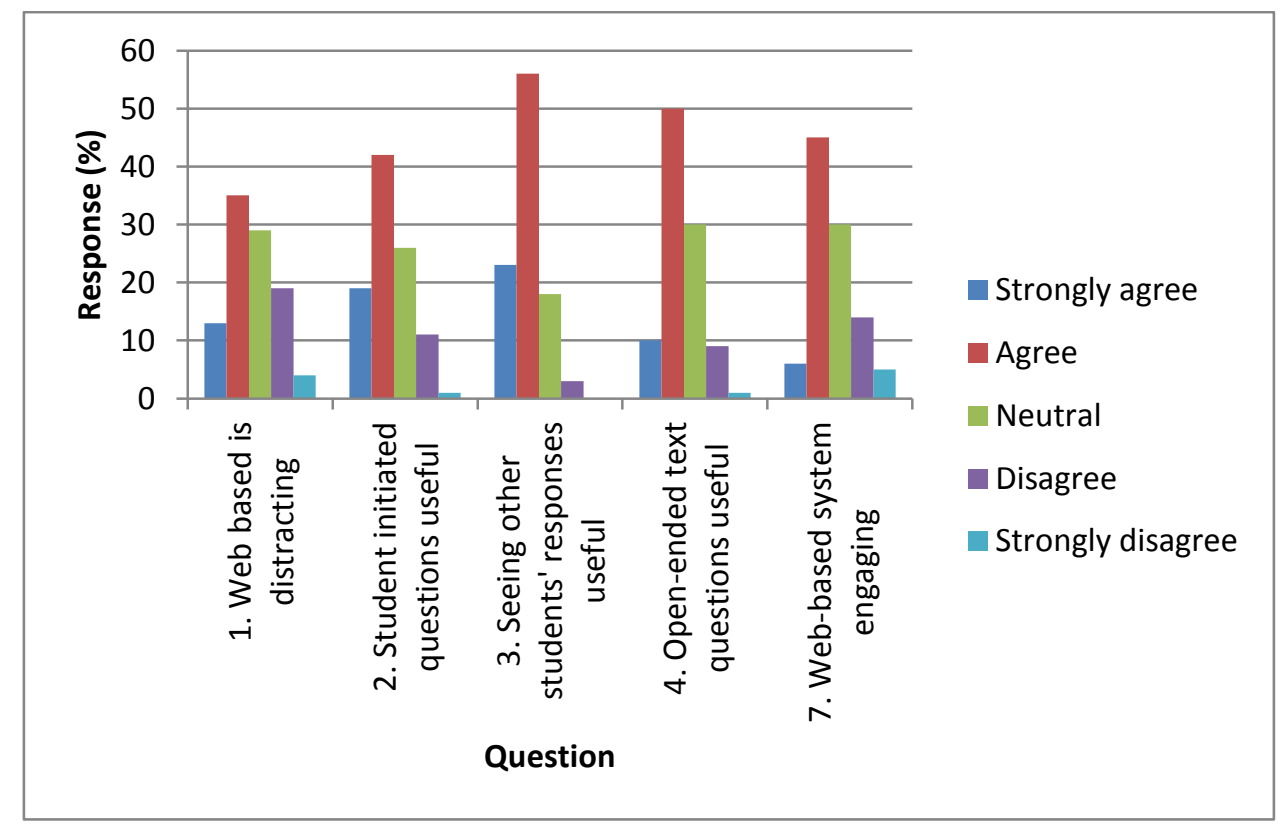

Figure 7 - Student survey responses on Likert-scale questions about the web-based ARS.

The survey results show both positive and negative aspects associated with using a web-based ARS. Almost half of the respondents felt that the web-based ARS could be distracting since they were required to have their browsers open during the lecture, and hence had easy access to email, Facebook, etc. More than half of the students felt that the ability for students to ask questions using the tool at any time was useful. The most positively viewed feature of the tools was the ability for the instructor to display and discuss other students' responses (Question 3: 79\% agreed or strongly agreed that it was useful.) Approximately $60 \%$ of the students felt that being able to answer and display open-text questions helped them learn (Question 4). Approximately half the students felt that the web-based system was engaging. 


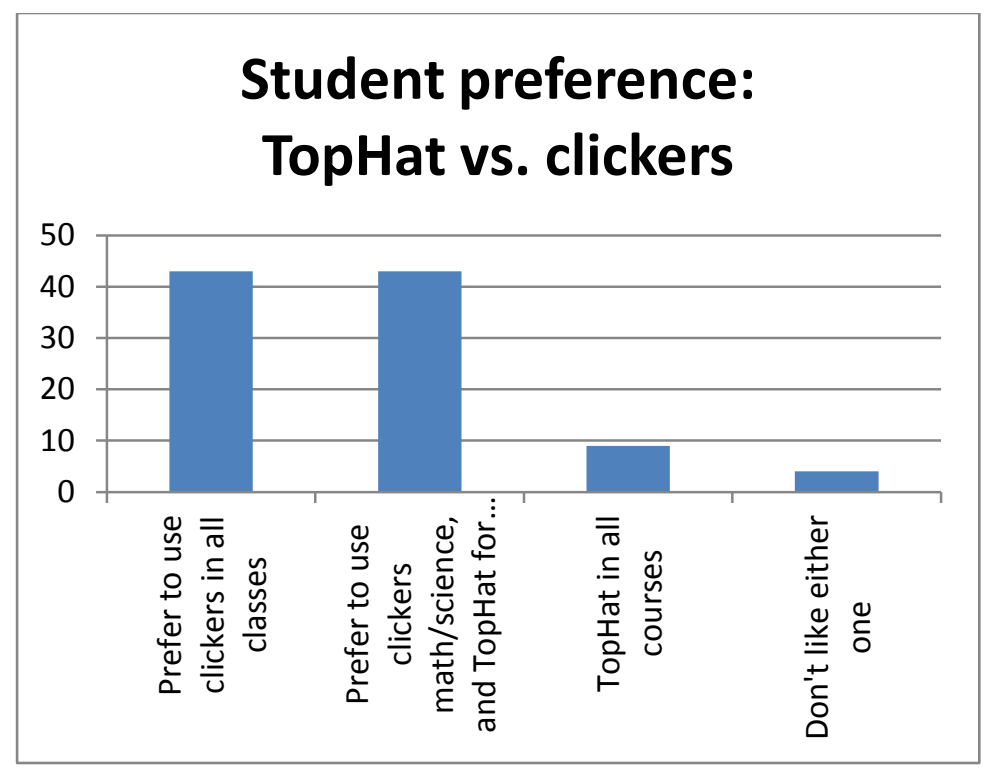

Figure 8 - Student preference for web-based vs. clickers (survey question 8).

Students were also asked a discussion question in TopHat:

- Please provide comments on the system, or suggestions for how course instructors can use a system like this.

A sample of student comments is shown below. On the subject of open-ended questions:

It's nice to be able to present entire opinions in written form when answering questions, as opposed to picking from a set of predefined answers. It would be nice if instructors used this more.

On the topic of comparing clickers with web-based ARS:

I like the ability to write the response, and how the instructor can read those responses and then state if it's a good idea or not. TopHat Monocle seems to fit with the lectures, and is a great way to involve participation. However, in physics or calculus, I find that the clickers are a better idea. There isn't much space to do math problems and have your laptop open, so the clickers fit best there. I like the variety of the two different programs.

I just feel that the turning point clickers are faster and simpler to use in lectures.

I like the fact that on TopHat, people could answer in their own words on occasion rather than having to choose from a given set of answer. I was more engaging, however, I do not think it was worth it with all the technical issues and 
distractions during class. I find that clickers are easier, faster and an overall better choice then TopHat, even if they are less engaging.

I think that there are very good ideas behind Tophat. However I don't think that it was used to its full potential. For example the area to ask questions anonymously at any point during the lecture and indicate when the lecture is going to fast or getting confusing is a good idea but I don't recall it ever actually being used. Turning point is simply more straight forward and easy to use. Tophat has potential to be a lot more powerful to as it allows for written feedback as opposed to just multiple choice answers, but it has technical issues and can be somewhat distracting and confusing.

I like that we can ask questions at any time, especially since it can be intimidating to ask a question verbally in class

I felt that the system was effective at giving fast, relevant information to the instructor, that they could use to supplement the lesson

Comments about technology issues:

Tophat was tough to use cause the internet was always slow in this class.

I found that I could not access tophatmonocle on many occasion. And as a result, I couldn't answer the questions that were assigned

I think that top hat would be useful if the internet connection here was more reliable. I don't see any advantages over a clicker until it works better.

Students generally felt that open-text questions and student initiated questions were useful, but both the instructor and students were adjusting to the technology. Students did not like having to bring laptops to the class, since no other class required this and students found that the system worked better with laptops than smartphones. The instructor found that the first delivery each week was integrated and more rushed than the same lecture delivered to another section later in the week. However, there was little variation in responses between lecture sections, despite the instructor feeling better prepared and more comfortable in the lecture section delivered at the end of each week. 


\section{Conclusions and Recommendations}

Students generally felt that the technological glitches with the system and network access and inconvenience of carrying laptop takes away from educational advantage of the student initiated questions and open-text responses. Students currently see little advantage in the system over clickers in courses where questions are predominantly closed-ended.

As with many new technologies, web-based ARS will require adjustment by both course instructor and students. Students currently feel that the system can be distracting; this may be partially alleviated by asking students to login to the system at the beginning of class but putting their laptops, tablets, and smartphones away while not being used for responses. These systems may be a significant adjustment for the course instructor, both in terms of moving between lecturing and asking questions, and in asking good open ended questions to prompt discussion.

In lectures where the objective is to work on critical thinking and communication development enriched with regular feedback, a possible approach is to use additional technology to allow students to collaboratively work on a short deliverable in class as monitored by instructor and TA in real time (rather than only when finally submitted), with periodic feedback to the class showing good quality and low-quality responses. This technology-assisted formative feedback would greatly shorten the feedback cycle, and supplement more detailed summative feedback provided when a student work is graded.

If the system is woven throughout the lecture it may be helpful to have a teaching assistant in class to help with the system, as it is challenging to simultaneously look for questions coming in, look for good student responses to post and discuss, answer questions, and lecture.

\section{References}

Bunce, D. M., VandenPlas, J. R., \& Havanki, K. L. (2006). Comparing the effectiveness on student achievement of a student response system versus online WebCT quizzes. Journal of Chemical Education, 83(3), 488.

Caldwell, J. E. (2007). Clickers in the large classroom: Current research and best-practice tips. CBE-Life Sciences Education, 6(1), 9-20.

Frank, B., \& Kaupp, J. (2012). Evaluating Integrative Model Eliciting Activities in First Year Engineering. In Proceedings of the 2012 Canadian Engineering Education Association (CEEA2012) Conference. Winnipeg, MB.

Frank, B., Strong, D., Sellens, R., \& Clapham, L. (2012). Progress With the Professional Spine: A Four-year Engineering Design and Practice Sequence. Presented at the 2012 International CDIO Conference, Brisbane, Australia.

Hake, R. R. (1998). Interactive-engagement versus traditional methods: A six-thousand-student survey of mechanics test data for introductory physics courses. American journal of Physics, 66, 64.

Hattie, J. (2008). Visible learning: A synthesis of over 800 meta-analyses relating to achievement. Routledge.

Hattie, J. (2009). The black box of tertiary assessment: An impending revolution. Tertiary Assessment \& Higher Education Student Outcomes: Policy, Practice \& Research, Ako Aotearoa, Wellington, New Zealand, pp. $259 A ́ 275$.

iClicker. (n.d.). I>clicker Classroom Response System. Retrieved January 3, 2013, from http://www.iclicker.com/ 
Jordan, S., \& Mitchell, T. (2009). e-Assessment for learning? The potential of short-answer free-text questions with tailored feedback. British Journal of Educational Technology, 40(2), 371-385. doi:10.1111/j.14678535.2008.00928.x

Kluger, A. N., \& DeNisi, A. (1996). The effects of feedback interventions on performance: A historical review, a meta-analysis, and a preliminary feedback intervention theory. Psychological bulletin, 119(2), 254.

Knight, J. K., \& Wood, W. B. (2005). Teaching more by lecturing less. Cell Biology Education, 4(4), 298-310.

Shuman, L. J., Besterfield-Sacre, M., Bursic, K. M., Vidic, N., \& Sieworiek, N. (2012). CCLI: MODEL ELICITING ACTIVITIES. In CD Proceedings: 2012 ASEE Annual Conference and Exposition. San Antonio, TX. Retrieved from http://www.asee.org/file_server/papers/attachment/file/0002/3592/ASEE-_Pitt_-_CCLINSF_-_2012-3.pdf

Top Hat Monocle. (n.d.). Classroom Response System - Home - Top Hat Monocle. Retrieved January 2, 2013, from http://tophatmonocle.com/

Turning Technologies. (n.d.). ResponseCard RF. Retrieved January 2, 2013, from http://www.turningtechnologies.com/response-solutions/responsecard-rf

Van Dijk, L. A., Van Der Berg, G. C., \& Van Keulen, H. (2001). Interactive lectures in engineering education. European Journal of Engineering Education, 26(1), 15-28.

Wood, D. (2009). A scaffolded approach to developing students' skills and confidence to participate in self and peer assessment. In ATN Assessment Conference 2009: Assessment in Different Dimensions (p. 374). Retrieved from http://www.postgradolinguistica.ucv.cl/dev/documentos/90,903,Perceptions_technologies_gruba_2009.pdf \#page $=374$ 